\title{
Accuracy of Fetal Weight Estimation in Women with Diet Controlled Gestational Diabetes
}

\author{
Wie genau ist die fetale Gewichtsschätzung \\ beim diätkontrollierten Gestationsdiabetes?
}

Authors

Affiliations
H. Husslein ${ }^{1}$, C. Worda ${ }^{2}$, H. Leipold ${ }^{1}$, Stefan Szalay ${ }^{1}$

${ }^{1}$ Department of Obstetrics and Gynecology, Landeskrankenhaus Klagenfurt, Klagenfurt, Austria

${ }^{2}$ Department of Obstetrics and Gynecology, Medical University Vienna, Allgemeines Krankenhaus der Stadt Wien, Wien, Austria

\section{Key words \\ - ultrasound \\ - estimated fetal weight \\ - gestational diabetes \\ Schlüsselwörter \\ - Ultraschall \\ - Gestationsdiabetes \\ - Gewichtsschätzung}

received $\quad 31.7 .2011$

revised $\quad 30.10 .2011$

accepted 11.1.2012

Bibliography

Dol http://dx.doi.org/

10.1055/s-0031-1298278

Geburtsh Frauenheilk 2012; 72 :

144-148 @ Georg Thieme

Verlag KG Stuttgart · New York . ISSN 0016-5751

\section{Correspondence}

Heinrich Husslein

Department of Obstetrics

and Gynecology

Landeskrankenhaus Klagenfurt

St. Veiterstraße 47

9020 Klagenfurt

Austria

heinrich.husslein@lkh-klu.at

\section{Abstract \\ $\nabla$}

Purpose: To evaluate whether ultrasound accuracy of estimated fetal weight (EFW) differs in women with diet controlled gestational diabetes mellitus (GDM) compared to nondiabetic pregnant women.

Material and Methods: We included 363 patients, 121 patients with diet controlled GDM and 242 patients with a normal oral glucose tolerance test (oGTT). Each case of diet controlled GDM was matched with 2 unaffected controls. All patients were screened/diagnosed for GDM by means of an oGTT. Both groups received ultrasound examination including fetal biometry, using Hadlock's Formula, within 7 days to delivery. After birth, gestational age, birthweight and Apgar scores were collected from each newborn.

Results: There was a good correlation between EFW and birth weight (coefficient $=0.747$, $\mathrm{p}<0.001$ by Pearson correlation, even after adjustment for glucose status). Regression analyses, including noGDM/GDM, maternal age, maternal body mass index, birth weight and time interval between ultrasound and delivery revealed that only fetal birth weight significantly influences weight difference between ultrasound EFW and actual birth weight at term.

Conclusion: Our data suggests that ultrasound accuracy of EFW using Hadlock's Formula at term does not differ in women with diet controlled GDM compared to women with normal glucose tolerance.

\section{Zusammenfassung \\ $\nabla$}

Fragestellung: $\mathrm{Zu}$ überprüfen, ob die fetale $\mathrm{Ge}-$ wichtsschätzung, im Rahmen des diätkontrollierten Gestationsdiabetes, weniger genau ist als bei Schwangeren ohne Gestationsdiabetes.

Material und Methodik: Es wurden insgesamt 363 Patienten eingeschlossen, davon 121 Schwangere mit diätkontrolliertem Gestationsdiabetes und 242 Schwangere ohne Glukosetoleranzstörung. Jeder Schwangeren mit Gestationsdiabetes wurden 2 Schwangere ohne Gestationsdiabetes gegenübergestellt. Bei allen Schwangeren wurde ein Screening für das Vorliegen eines Gestationsdiabetes mittels eines oralen Glukosetoleranztests durchgeführt. Bei beiden Gruppen wurde eine fetale Gewichtsschätzung mit der Hadlock-Formel, maximal 7 Tage vor der Geburt, durchgeführt. Nach der Geburt wurden das Gestationsalter, das Geburtsgewicht und der Apgar des jeweiligen Neugeborenen notiert, und das tatsächliche Geburtsgewicht wurde mit der Gewichtsschätzung verglichen.

Ergebnisse: Insgesamt stimmen das tatsächliche Geburtsgewicht und die Gewichtsschätzung gut miteinander überein (Koeffizient $=0,747$, $\mathrm{p}<0,001$ nach Pearson-Korrelation, auch nach Abgleichung mit dem Glukosestatus). Die Regressionsanalyse, welche die Parameter Gestationsdiabetes/kein Gestationsdiabetes, mütterliches Alter, mütterlicher Body-Mass-Index, Geburtsgewicht und Zeitintervall zwischen dem Zeitpunkt der Gewichtsschätzung und der Geburt beinhaltet, zeigt, dass nur das Geburtsgewicht einen Einfluss auf die Genauigkeit der Gewichtsschätzung hat.

Folgerung: Anhand dieser Daten scheint die Gewichtsschätzung im Rahmen des diätkontrollierten Gestationsdiabetes nicht weniger genau zu sein als bei Schwangeren ohne Gestationsdiabetes. 


\section{Introduction}

\section{$\nabla$}

Diabetes in pregnancy is one of the most common pregnancy complications, with a prevalence of 5 to $10 \%$ and a major cause of maternal and fetal morbidity [1]. Gestational diabetes mellitus (GDM), which represents approximately $90 \%$ of cases in which pregnancy is complicated by impaired glucose metabolism [2], is defined as development of glucose intolerance during pregnancy or glucose intolerance that is first detected during pregnancy [3]. Women with GDM appear to be at increased risk for fetal macrosomia and perinatal complications if treatment is not provided [4]. The exact pathogenesis of GDM is not completely understood; however, increased insulin resistance is a well-demonstrated mechanism [5]. GDM can be classified according to White's classification. White's classification A1 comprehends cases of GDM where glucose metabolism is diet controlled only, whereas in White's classification A2 glucose levels must be controlled with insulin treatment [6].

Fetal macrosomia can be defined in several ways. One commonly used weight threshold is fetal birth weight greater 4500 grams, as supported by the American College of Obstetricians and Gynecologists [7].

There is evidence for a strong continuous association between maternal glucose concentrations and increasing birth weight, cord-blood serum C-peptide levels, and other markers of perinatal complications $[4,8]$. A study comparing fetal outcome of mothers with diet controlled and insulin controlled GDM described a significantly higher incidence of fetal macrosomia in the group of GDM that was insulin controlled [9]. Consequently it can be hypothesized that GDM requiring insulin treatment is a more severe form of glucose intolerance during pregnancy than diet controlled GDM, causing more complications linked to maternal hyperglycaemia.

There are controversial reports concerning ultrasound accuracy of EFW in diabetic mothers. Some authors suggest that EFW is less accurate in infants of diabetic mothers, due to different allocation of soft tissue [10]. Macrosomic infants of diabetic mothers have increased soft tissue mass around the trunk and limbs [11, 12]. Therefore, Wong et al. and other authors conclude that EFW measurement in fetuses of diabetic mothers is rather underestimating the actual birth weight since standard formulas for fetal weight estimation are not taking these anthropometric changes into account $[9,13]$.

Other studies report similar or better accuracy of EFW in diabetic compared to nondiabetic pregnant women $[14,15]$. A review on the detection and treatment of the macrosomic fetus suggested that EFW and detection of fetal macrosomia is more accurate in diabetic and postdate pregnancies. However the authors concluded that better accuracy of EFW is due to a higher prevalence of macrosomia in these two groups and not due to better ultrasound accuracy of EFW [16].

None of these studies are distinguishing between diet controlled and insulin treated GDM or preexisting diabetes. This might be a reason for varying study results.

The objective of this study is to evaluate whether the ultrasound accuracy of EFW differs in women with diet controlled GDM (White's classification A1) compared to nondiabetic pregnant women.

\section{Materials and Methods \\ 7}

The study was conducted between 2007 and 2009 at the Department of Obstetrics and Gynaecology at the Landeskrankenhaus Klagenfurt, Austria, a tertiary care centre serving high-risk pregnancies with different pregnancy-associated complications. Clinical investigations were conducted in accordance with the Declaration of Helsinki. All women were Caucasian. Patients younger than 18 years, with multiple pregnancies, preexisting diabetes, gestational diabetes that required insulin treatment (White's classification A2), fetal anomalies, patients taking corticosteroids and patients with chronic diseases were excluded from the study. We included 363 women in our study, 121 women with diet controlled GDM (White's classification A1) and 242 women with a normal oral glucose tolerance test. Each case of GDM was matched with 2 unaffected controls. All women were diagnosed having GDM by means of an oral glucose tolerance test (oGTT). Patient characteristics, including body mass index (BMI) value, are routinely collected during the first visit at our institution. The oGTT was conducted between 24 and 28 weeks of gestation. We used a standardized 75-g glucose solution (Glucodrink ${ }^{\circledR}$, Unipack, Wr. Neustadt, Austria). The test was performed in the morning after a fasting period of a minimum of 8 hours. Blood was drawn in the fasting state and 1 hour and 2 hours after glucose drink intake. The guidelines of the German and the Austrian Society for Diabetes (modified Carpenter Coustan criteria) were implemented for evaluation of the OGTT [17]. The upper normal limit for fasting, one hour, and two hour serum glucose was $90 \mathrm{mg} / \mathrm{dL}$ (5,0 mmol/L), $180 \mathrm{mg} / \mathrm{dL}$ (10,0 mmol/L) and $155 \mathrm{mg} / \mathrm{dL}$ $(8,6 \mathrm{mmol} / \mathrm{L})$, respectively. If at least one value was exceeded, GDM was diagnosed, and glucose monitoring and dietary instructions were started. As control group we took women with a physiological oGTT. Women diagnosed with GDM obtained dietary counselling by a trained dietary assistant and were instructed to measure capillary glucose levels on a daily basis during fasting state and 1 hour after meal. Glucose levels were rated as normal if fasting glucose did not exceed $90 \mathrm{mg} / \mathrm{dL}(5,0 \mathrm{mmol} / \mathrm{L})$ and $130 \mathrm{mg} / \mathrm{dL}(7,2 \mathrm{mmol} / \mathrm{L})$ one hour postprandially. If these limits were exceeded 5 times or more within the first week, insulin therapy was initiated in close collaboration with the department of internal medicine at our hospital. These women requiring insulin treatment were excluded from our study.

Women were monitored on a weekly or two weekly basis, depending on their metabolic situation and fetal biometrical data. At each visit mean glucose values were calculated for the last two week period. Labour was induced using vaginal prostaglandin application at term in all women with diet controlled GDM, unless it occurred spontaneously. The control group received medical induction of labour 10 days past term.

Both groups received an ultrasound examination including fetal biometry and EFW measurement within seven days to delivery. Women without ultrasound examination within seven days of delivery were excluded. In order to minimize inaccuracy due to worse visualization, we matched both groups according to BMI values. A Voluson E8 expert (GE Healthcare-Product Technology, Fairfield, USA), was used. Head circumference (HC), biparietal diameter (BPD), abdomen circumference (AC) and femur length (FL) were measured in a standard fashion [18]. The estimated fetal weight (EFW) was calculated using Hadlock's formula [19]. We used Hadlock's Formula because it has been described that Hadlock's Formula and Shepard's Formula are the most accurate formulas for EFW measurement at term [20]. 
After birth, gestational age, birth weight and Apgar scores were collected from each included newborn.

Statistical analyses were performed with SPSS software (version 15.0; SPSS, Chicago, IL). Continuous variables are summarized as means ( \pm standard deviation), and categorical data as percentages. $\mathrm{X}^{2}$ test, t-test, Pearson correlation, and linear and logistic multiple regression analysis were used accordingly. For the logistic regression analysis the backward selection with likelihood ratio test was used. The goodness quality of fit of models was assessed using the Hosmer and Lemeshow test. Independent variables entered into the regression models were noGDM/GDM, maternal age, maternal body mass index, birth weight and time interval between ultrasound and delivery. P values of $<0.05$ were considered significant.

\section{Results}

Overall 363 pregnant women were included in the study. 121 women had diet controlled GDM and 242 women had normal glucose tolerance. Patient characteristics are shown in $\odot$ Table 1. Patients with GDM were significantly older $(32.6 \pm 6.0$ years, $32.1 \pm 6.0$ years; $p<0.001$ by t-test) and had a significantly lower gestational age at delivery (39.4 \pm 1.7 weeks, $40.6 \pm 0.9$ weeks; $\mathrm{p}<0.001$ by t-test) than pregnant women with normal glucose tolerance. Data on maternal glucose levels were $83,82 \mathrm{mg} / \mathrm{dL}$ (range 73-92) in the fasting state, $119,16 \mathrm{mg} / \mathrm{dL}$ (range 97-133) one hour after breakfast, $120,35 \mathrm{mg} / \mathrm{dL}$ (range 98-133) one hour after lunch and $121,38 \mathrm{mg} / \mathrm{dL}$ (range 97-133) one hour after dinner indicating that target glycemic thresholds were achieved. Patients had an average of six prenatal visits. As expected there was a good correlation between EFW and birth weight (coefficient $=0.747, \mathrm{p}<0.001$ by Pearson correlation, even after adjustment for glucose status).

Regression analyses, including no GDM/GDM, maternal age, maternal body mass index, birth weight and time interval between ultrasound and delivery revealed that only fetal birth weight significantly influences weight difference between ultrasound EFW and actual birth weight at term (O Table 2).

Using Hadlock's formula we compared the EFW measured within 1 week prior to delivery with fetal birth weight in women with diet controlled GDM and women with normal glucose tolerance. There was no statistically significant difference between these two groups $(6.9 \pm 6.1 \%, 8.0 \pm 7.3 \% ; \mathrm{p}=0.17$ by t-test). Furthermore we have stratified the subjects in 5 different groups based on fetal birth weight. In none of the birth weight classes a significant difference in percent error could be observed. The highest percentages were observed in fetuses below $3000 \mathrm{~g}$ and fetuses above $4000 \mathrm{~g}$ (11.3 and 10\%), but this difference did not reach significance (@ Table 3$)$.

\section{Discussion}

In most departments EFW measurement at term is performed. The majority of American College of Obstetrics and Gynecology fellows are using ultrasound for fetal weight estimation at term and $84 \%$ are recommending a cesarean section if EFW is greater than $4500 \mathrm{~g}$ [21]. Birth weight represents the most important risk indicator for neonatal and infant mortality and morbidity [22]. An accurate EFW is valuable information for planning the mode of delivery and management of labor, especially in diabetic
Table 1 Patient characteristics $(n=363)$.

\begin{tabular}{|c|c|c|c|}
\hline & Controls & GDM & P value* \\
\hline Patients ( $\mathrm{n}$ ) & 242 & 121 & \\
\hline Age (years) & $29.3 \pm 5.5$ & $32.1 \pm 6.0$ & $<0.001$ \\
\hline Primipara (\%) & 52.7 & 52.1 & 0.91 \\
\hline $\begin{array}{l}\text { Body mass index } \\
\left(\mathrm{kg} / \mathrm{m}^{2}\right)\end{array}$ & $27.7 \pm 4.5$ & $28.0 \pm 5.7$ & 0.52 \\
\hline $\begin{array}{l}\text { Gestational age } \\
\text { at delivery (weeks) }\end{array}$ & $40.6 \pm 0.8$ & $39.4 \pm 1.7$ & $<0.001$ \\
\hline Birth weight (g) & $3509 \pm 446$ & $3475 \pm 593$ & 0.73 \\
\hline $\begin{array}{l}\text { Estimated } \\
\text { birth weight (g) }\end{array}$ & $3493 \pm 391$ & $3554 \pm 559$ & 0.91 \\
\hline $\begin{array}{l}\text { Ultrasound } \\
\text { before delivery (days) }\end{array}$ & $3.5 \pm 2.2$ & $3.42 \pm 2.1$ & 0.81 \\
\hline Weight difference (g) & $271.4 \pm 210.5$ & $248.5 \pm 226.8$ & 0.24 \\
\hline Weight difference (\%) & $8.0 \pm 7.3$ & $6.9 \pm 6.1$ & 0.16 \\
\hline Apgar 5 minutes & $9.8 \pm 1.0$ & $9.8 \pm 0.6$ & 0.90 \\
\hline Apgar 10 minutes & $9.8 \pm 1.3$ & $9.9 \pm 0.3$ & 0.22 \\
\hline
\end{tabular}

$\mathrm{GDM}=$ gestational diabetes mellitus, ${ }^{*}$ t-test or $\mathrm{X}^{2}$, values are given as mean $\pm \mathrm{SD}$ or percentages

Table 2 Predictors of weight difference at time of delivery between ultrasound estimated weight and birth weight in women delivered at term.

\begin{tabular}{|c|c|c|c|c|c|}
\hline \multicolumn{2}{|c|}{ Model } & \multirow{2}{*}{$\begin{array}{l}\text { Coeffi- } \\
\text { cient } \\
-114.084\end{array}$} & \multirow{2}{*}{$\begin{array}{l}\text { Std. } \\
\text { Error } \\
118.597\end{array}$} & \multirow[t]{2}{*}{ Beta } & \multirow{2}{*}{$\begin{array}{r}\text { p-value } \\
0.337\end{array}$} \\
\hline 1 & (Constant) & & & & \\
\hline & $\begin{array}{l}\text { Body mass } \\
\text { index }\end{array}$ & 1.544 & 2.704 & 0.032 & 0.569 \\
\hline & $\begin{array}{l}\text { Time interval } \\
\text { ultrasound } \\
\text { and delivery }\end{array}$ & -1.871 & 5.894 & -0.017 & 0.751 \\
\hline & nonGDM/GDM & -42.949 & 27.843 & -0.083 & 0.124 \\
\hline & Birth weight & 0.090 & 0.027 & 0.185 & 0.001 \\
\hline & Age & 1.490 & 2.175 & 0.037 & 0.244 \\
\hline \multirow[t]{5}{*}{2} & (Constant) & -118.658 & 117.564 & & 0.314 \\
\hline & $\begin{array}{l}\text { Body mass } \\
\text { index }\end{array}$ & 1.520 & 2.700 & 0.031 & 0.574 \\
\hline & nonGDM/GDM & -42.916 & 27.807 & -0.083 & 0.124 \\
\hline & Birth weight & 0.089 & 0.027 & 0.184 & 0.001 \\
\hline & Age & 1.500 & 2.172 & 0.037 & 0.490 \\
\hline \multirow[t]{4}{*}{3} & (Constant) & -94.922 & 109.634 & & 0.387 \\
\hline & nonGDM/GDM & -42.863 & 27.779 & -0.083 & 0.124 \\
\hline & Birth weight & 0.093 & 0.026 & 0.192 & $<0.001$ \\
\hline & Age & 1.647 & 2.154 & 0.041 & 0.445 \\
\hline \multirow[t]{3}{*}{4} & (Constant) & -48.421 & 91.161 & & 0.596 \\
\hline & nonGDM/GDM & -38.855 & 27.263 & -0.075 & 0.155 \\
\hline & Birth weight & 0.094 & 0.026 & 0.193 & $<0.001$ \\
\hline \multirow[t]{2}{*}{5} & (Constant) & -57.605 & 91.068 & & 0.527 \\
\hline & Birth weight & 0.093 & 0.026 & 0.192 & $<0.001$ \\
\hline
\end{tabular}

Dependent variable: Difference between estimated birth weight and birth weight

pregnancies with a higher incidence of fetal macrosomia, since fetal macrosomia is associated with shoulder dystocia, brachial plexus injury, clavicular fracture, maternal birth trauma and cesarean section [23-25]. Since EFW measurement at term is frequently performed and influences birth mode [21], we believe that knowledge about the accuracy of EFW and consequently reliability of this diagnostic tool in different clinical situations is important.

Data on ultrasound accuracy of EFW measurement in diabetic pregnancies is controversial. There are studies reporting better, less and equal ultrasound accuracy of EFW [9,12-14]. 
Table 3 Mean absolute percent difference for ultrasound estimated birth weight and birth weight in fetuses of women with GDM and normal glucose tolerance.

\begin{tabular}{|lllccc|}
\hline Birth weight & GDM & \multicolumn{3}{c}{ Controls } & $\mathbf{P}^{*}$ \\
& Number & \% Difference & Number & \% Difference & \\
\hline$<3000 \mathrm{~g}$ & 19 & $6.8(6.7)$ & 32 & $11.3(11.0)$ & 0.15 \\
\hline $3000-3500 \mathrm{~g}$ & 44 & $6.8(6.2)$ & 93 & $7.1(5.1)$ & 0.76 \\
\hline $3500-4000 \mathrm{~g}$ & 38 & $6.1(4.8)$ & 83 & $7.2(6.5)$ & 0.39 \\
\hline $4000-4500 \mathrm{~g}$ & 11 & $9.2(7.3)$ & 30 & $10.0(7.7)$ & 0.74 \\
\hline$>4500 \mathrm{~g}$ & 9 & $8.8(7.4)$ & 4 & $8.7(7.4)$ & 0.45 \\
\hline Total & $\mathbf{1 2 1}$ & $\mathbf{6 . 9 ( 6 . 1 )}$ & $\mathbf{2 4 2}$ & $\mathbf{8 . 0 ( 7 . 3 )}$ & $\mathbf{0 . 1 7}$ \\
\hline
\end{tabular}

Values given as absolute numbers or mean (SD), GDM = gestational diabetes mellitus, ${ }^{*}$ by t-test

However, most studies are not discriminating different forms of diabetes in pregnancy. Women with diet controlled GDM, insulin controlled GDM, preexisting diabetes mellitus type I and preexisting diabetes mellitus type II are often rated as "diabetic pregnancies". This might be a reason for varying study results.

Differences in EFW accuracy are ascribed to different allocation of fetal soft tissue in fetuses of women with GDM. In poorly controlled diabetic pregnancies, newborn have different anthropometric features showing more soft tissue around the trunk and limbs compared to newborn of women with regular glucose metabolism $[10,11]$. Higher maternal serum glucose levels result in higher insulin concentration in the amniotic fluid and thereby affect fetal abdominal growth [26].

A novelty of our study is that the study population consists only of women with diet controlled GDM (White's classification A1), the mildest form of diabetes in pregnancy. If adequate glucose levels were not achieved with diet control, mothers were treated with insulin and excluded from the study. Furthermore we matched our groups according to BMI value, in order to minimize inaccuracy caused by worse visualization of the fetus during ultrasound examination. We deliberately decided to include only pregnancies with diet controlled GDM (White's classification A1) because we believe that, as described above, pooling of different types of diabetes in pregnancy might be one reason for divergent results of previous studies comparing ultrasound accuracy of EFW in pregnancies complicated by diabetes and pregnancies with normal glucose tolerance.

Our results show no difference concerning ultrasound accuracy of EFW at term in pregnant women with diet controlled GDM compared to women with normal glucose tolerance. We only found fetal birth weight to influence the accuracy of EFW measurements.

\section{Conclusions}

\section{$\nabla$}

The accuracy of ultrasound to estimate fetal weight at term in women with diet controlled GDM (White's classification A1) seems to be as reliable as EFW in unaffected pregnancies. The highest weight differences in percent error were observed in fetuses below $3000 \mathrm{~g}$ and fetuses above $4000 \mathrm{~g}$ (11.3\% and 10\%), which is in concordance with other studies [27].

\section{Conflict of Interest}

There is no conflict of interest to be disclosed. The authors alone are responsible for the content and writing of the paper.

\section{References}

1 Sepe SJ, Connell FA, Geiss LS et al. Gestational diabetes. Incidence, maternal characteristics and perinatal outcome. Diabetes 1985; 34 (Suppl. 2): 13-16

2 Gabbe S, Graves C. Management of diabetes mellitus complicating pregnancy. Obstet Gynecol 2003; 102: 857-868

3 ACOG Practice Bulletin. Clinical management guidelines for obstetrician-gynecologists. Number 30. Gestational diabetes. Obstet Gynecol 2011; 98: 525-538

4 Landon MB, Spong CY, Thom E et al. A multicenter randomized trial of treatment for mild gestational diabetes. N Engl J Med 2009; 361: $1339-1348$

5 Buchanan TA, Xiang AH. Gestational diabetes mellitus. J Clin Invest 2005; 115: 485-491

6 White P. Pregnancy complicating diabetes. Am J Med 1949; 7: 609

7 Chatfield J. ACOG issues: Guidelines on fetal macrosomia. American College of Obstetricians and Gynecologists. Am Fam Physician 2001; 64: $169-170$

8 Metzger BE, Lowe LP, Dyer AR et al. Hyperglycemia and adverse pregnancy outcomes. N Engl J Med 2008;358: 1991-2002

9 Suhonen L, Hiilesmaa V, Kaaja $R$ et al. Detection of pregnancies with high risk of fetal macrosomia among women with gestational diabetes mellitus. Acta Obstet Gynecol Scand 2008; 87: 940-945

10 Benson CB, Doubilet PM, Saltzman DH. Sonographic determination of fetal weights in diabetic pregnancies. Am J Obstet Gynecol 1987; 156: 441-444

11 Modanlou HD, Komatsu C, Dorchester W et al. Large for gestational age neonates: anthropometric reasons for shoulder dystocia. Obstet Gynecol 1982; 60: 417-423

$12 \mathrm{Kehl}$ RJ, Krew MA, Thomas A et al. Fetal growth and body composition in infants of women with diabetes mellitus during pregnancy. J Matern Fetal Med 1996; 5: 273-280

13 Wong SF, Chan FY, Cincotta RB et al. Sonographic estimation of fetal weight in macrosomic fetuses: diabetic versus non-diabetic pregnancies. Aust N Z J Obstet Gynaecol 2001; 41: 429-432

14 Alsulyman 0 , Ouzounian J, Kjos S. The accuracy of intrapartum ultrasonographic fetal weight estimation in diabetic pregnancies. Am J Obstet Gynecol 1997; 177: 503-506

15 Mclaren R, Puckett J, Chauhan S. Estimators of birth weight in pregnant women requiring insulin: a comparison of seven sonographic models. Obstet Gynecol 1995; 85: 565-569

16 Chauhan SP, Grobman WA, Gherman RA et al. Suspicion and treatment of the macrosomic fetus: a review. Am J Obstet Gynecol 2005; 193: 332-246

17 Kautzky-Willer A, Bancher-Todesca D. Gestational diabetes mellitus. Acta Med Austriaca 2004; 31: 182-184

18 Schneider H, Husslein P, Schneider KTM. Die Geburtshilfe. 4. Auflage. Heidelberg: Springer Medizin Verlag; 2010

19 Hadlock F, Harrist $R$, Carpenter $R$ et al. Sonographic estimation of fetal weight. The value of femur length in addition to head and abdomen measurements. Radiology 1984; 150: 535-540

20 Mirghani HM, Weerasinghe S, Ezimokhai M et al. Ultrasonic estimation of fetal weight at term: an evaluation of eight formulae. J Obstet Gynaecol Res 2005; 31: 409-413

21 Landon MB, Mintz MC, Gabbe SG et al. Management of diabetes mellitus and pregnancy: a survey of obstetricians and maternal-fetal specialists. Obstet Gynecol 1990; 75: 635-640

22 Arias E, MacDorman MF, Strobino DM et al. Annual summary of vital statistics 2002. Pediatrics 2003; 112: 1215-1230 
23 Metzger BE, Lowe LP, Dyer AR et al. Hyperglycemia and adverse pregnancy outcomes. N Engl J Med 2008; 358: 1991-2002

24 Kwik M, Seeho SK, Smith C et al. Outcomes of pregnancies affected by impaired glucose tolerance. Diabetes Res Clin Pract 2007; 77: 263-268

25 Crowther CA, Hiller JE, Moss JR et al. Effect of treatment of gestational diabetes mellitus on pregnancy outcomes. N Engl J Med 2005; 352: 2477-2486
26 Schaefer-Graf UM, Kjos SL, Bühling KJ et al. Amniotic fluid insulin levels and fetal abdominal circumference at time of amniocentesis in pregnancies with diabetes. Diabet Med 2003; 20: 349-354

27 Scioscia M, Vimercati A, Ceci O et al. Estimation of birth weight by twodimensional ultrasonography: a critical appraisal of its accuracy. Obstet Gynecol 2008; 111: 57-65 